\title{
CIENCIA Y VIDA: ¿UNA IMPOSIBLE CONJUNCIÓN?
}

\author{
José Luis Peset
}

I. H. - C.S.I.C.

\section{RESUMEN}

Se presentan en este artículo las principales tendencias en historia biográfica, centrándose en historia de la ciencia. La biografía de los científicos tiene algunas peculiaridades. Se discuten los modelos internos y externos, procedentes de teorías lógicas, sociológicas y culturales. El biógrafo debe escoger, modelando su personaje de acuerdo con sus puntos de vista científicos, culturales e ideológicos.

PALABRAS CLAVE: Historiografía, biografía.

\section{SUMMARY}

This paper presents the main trends in biographical history, focusing on history of science. The biography of scientists has some peculiarities. Internal and external models, comming from logical, sociological and scientific theories are discussed. The biographer is obliged to choose, modeling his subject according his scientific, cultural and ideological points of view.

KEY WORDS: Historiography, biography.

Hace años, muchos años, cuando un grupo de amigos empezamos a formar la Sociedad Española de Historia de las Ciencias, recuerdo que Santiago Garma, su primer Presidente, siempre nos hablaba emocionado de la biografía de Evariste Galois, un insigne matemático francés, perteneciente al período romántico. Y romántica fue su vida, desde luego, como las de muchos de sus coetáneos. Si bien en el pretérito la vita brevis era usual, uno piensa en quienes vivieron y participaron en el mundo romántico y se sorprende de que sus vidas respondan tan bien al estereotipo que ellos mismos forjaron. Vidas cortas, azarosas y conflictivas, en las que las separaciones entre naturaleza y sociedad se muestran de forma asfixiante. Recordemos, por ejemplo, a los compositores de ópera italianos, a los grandes escritores Donizetti y Bellini, 
en sus vidas apasionadas ${ }^{1}$. Casi parecen haber adelantado ese dicho tan célebre de la filmografía negra americana, vive rápido, muere joven y tendrás un hermoso cadáver. Por el contrario Rossini, heredero de la Ilustración, y Verdi, ya en el mundo del positivismo, vivieron vidas largas y ostentosamente apacibles. ¿Porqué esa semejanzas de vida en ciertos momentos culturales? Sin duda, esos modelos pueden estar en el mismo biografiado, por su voluntad o por circunstancias, sean guerras o enfermedades, valores o instituciones. Sin duda algunas enfermedades pueden ahormar vidas, si bien la sífilis, o la locura, buscadas o halladas, no hermosean la vida ni la muerte. Pero también esos modelos pueden ser un intento del biógrafo por remodelar al autor, a una tradición o a su mundo propio.

Nos dice René Taton reiteradamente que Galois no ha recibido el estudio, ni la biografía que merece. Nos señala el Dictionary of Scientific Biography, su breve vida entre 1811 y 1832 , su dependencia de los caracteres de su padre y su madre, sus conflictos vitales frecuentes. Es expulsado de centros docentes, es militar republicano y agitador político, es un prisionero y un científico despreciado, incluso se pierden sus papeles presentados para un premio en la Academia. Estudia en la Restauración en el Collège Louis-le-Grand, en l'École Normal, tras el fracaso en ingresar en la Politécnica, participando en la revolución de 1830 con sus amigos Blanchi y Raspail. Episodios amorosos, encarcelamientos y un reto final acaban con su vida con una veintena de años. Adivinando su muerte en el duelo, escribe cartas con resultados científicos, que sus amigos guardan. Seguidor de Abel, con quien soluciona a la vez las ecuaciones de $5^{\circ}$ grado, revoluciona el álgebra moderna en la segunda mitad del siglo, al ser publicadas sus obras en $1846^{2}$. Nos emociona pensar en el consuelo que encontró en su última noche en unas ecuaciones matemáticas, la misma que Condorcet halló al trazar el imparable camino de perfección de la ciencia moderna en sus últimas páginas.

Sin duda, nos encontramos con una maravillosa vida, una biografía tal vez todavía no escrita, que nos puede hacer reflexionar. Quizá ese carácter tan intimista de las matemáticas ha alejado a los biógrafos, a pesar de esa «contaminación» con la política, la sexualidad y la muerte ${ }^{3}$. El fin de la vida carnal

1 Lo mismo se puede decir de la vida y obra de escritores como Kleist o Hölderlin.

2 TAton, R. (1972), «Evariste Galois», en Charles Coulston Gillispie (ed.), Dictionary of Scientific Biography, New York, Charles Scribner's Sons, V, pp. 259-265. Ligou, D. (1968), François-Vincent Raspail ou le bon usage de la prison, París, Jérôme Martineau.

3 Por el contrario otros personajes como Jorge Juan han encontrado buenos biógrafos. Se trata de un marino de vida ordenada, cuyos aportes se centran en la aburrida mecánica de 
es en este personaje el principio de la vida de la gloria, la pasión amorosa es el fin de la biografía, pero tal vez abre la verdadera carrera científica. Quizá la forma de biografía «romántica» desagrade a los historiadores de la ciencia, más partidarios de las biografías de cuño «clasicista». ¿Es por tanto compatible la Vida con la Ciencia, es posible pues una biografía de un científico? Como escribió Jules Verne sobre el futuro de la música, ¿es posible entusiasmarse por una obra de Euterpe que se denominase Ensoñaciones en La menor sobre el cuadrado de la hipotenusa? ${ }^{4}$

De todas formas, biografías de científicos las hay, muchas y muy buenas en algunos casos. Sin duda más tardías que las historias de los héroes, santos o artistas, en el mundo moderno abundan, cuando la revolución científica y sus instituciones triunfan. Los clásicos elogios de Fontenelle son un buen ejemplo, intentando mostrar la valía humana y el talento científico de los biografiados. Sin duda, es seguido el ejemplo de los modelos señalados, en último término trasuntos de las grandes biografías, la de Hércules, el dios hombre, y la de Cristo, el hombre dios. Tomemos un ejemplo, una de las biografías escritas y pronunciadas por el secretario en la Académie Royale de Médicine. Para ello me serviré del libro de E. F. Dubois, Histoire des membres de l'Académie Royale de Médecine, editado en París, en 1850. Dubois es el secretario perpetuo, que sucede a Pariset, quien lo fue desde la fundación. Publica el discurso de apertura, así como los elogios hechos por su antecesor, al que añade su propio elogio a éste. Quiere publicar los de las otras academias ilustradas, los de Louis y Vicq d'Azyr, el primero para la Académie Royale de Chirurgie, el segundo para la Société Royale de Médécine 5 .

Tomemos, como digo, como ejemplo la que Pariset escribió sobre el barón de Corvisart. Reúne aspectos anecdóticos, con otros de tipo científico e institucional que jalonan la brillante carrera del médico del Emperador. Aspectos humanos van marcando las dificultades y los éxitos de su vida, convirtiéndolo en personaje excepcional, en un héroe más de las gestas napoleónicas. Su nacimiento en 1755 está señalado por el terremoto de Lisboa y por las peleas

fluidos. Pero su relación con la marina y por tanto con el mundo de los viajes hace atrayente su figura. SOLER, E. (2002), Viajes de Jorge Juan y Santacilia, Barcelona, Ediciones B.

4 En la novela Amiens en el año 2000, véase el texto de Javier Roca sobre «A. Schönberg» para Orquestas del Mundo de Ibermúsica, Madrid, 29 de mayo de 2004.

5 Dubois, E. F. (1850), Histoire des membres de l'Académie Royale de Médecine, ou Recueil des éloges lus dans les séances publiques par E. Pariset, París, 2 vols., J. B. Baillière, Libraire de l'Académie Nationale de Médecine. 
entre el parlamento y la iglesia, que obligan a su padre, miembro de aquél, a marcharse de París. Su madre, y la mujer en general, no aparece, pero su padre vuelve a surgir cuando, demasiado sensible y apasionado por la pintura, que también pienso que amó su hijo, pierde su riqueza en peligrosa compra de cuadros. Educado en un pueblo por su tío sacerdote, se inicia en la religión, en el latín y el francés, así como en las canciones de allí que recordará y que canta a la vejez, en la enfermedad quizá.

De su época de niño se aprovecha poco, en poco se señala, pues como él mismo afirmaba hasta los 25 años nada distingue al hombre selecto. Justeza de ideas y destreza de movimientos, son sin embargo sus destacadas marcas primeras. Su padre quiere retenerlo en el bufete, pero se escapa inquieto a los extraordinarios hospitales de París, juntándose con grandes maestros. Es ayudante de disección y se hiere, puede perder el brazo pero lo salva Pierre- Joseph Desault. Se trata, sin duda, de otro favor de la fortuna y la ciencia. Entra en la Facultad de Medicina, volcándose a la interna, pero con la precisión de la cirugía. Lee primero una tesis latina y entrará luego como Doctor regente de la Faculté, disertando sobre enseñanza y práctica de la medicina. Profesor adjunto de anatomía, enseña también fisiología, cirugía y partos. A pesar de su poco dinero, atenderá a los pobres en Saint Sulpice. No ingresa en un caritativo hospital creado por una dama, porque debía llevar peluca. Una nueva aparición de la mujer, sin duda una señora del Antiguo Régimen, que no comprende la modernidad del pelo descubierto. El maestro Jesús Pavón señalaba cómo Franklin al navegar hacia Francia para conseguir su apoyo, arroja al mar también la vieja peluca. Es la juventud y la modernidad contra el pasado ${ }^{6}$.

Llega Corvisart al hospital de la Charité, donde escucha y edita a Louis Desbois de Rochefort, a quien continúa en la moda de las lecciones clínicas, gran ejercicio de la enseñanza práctica francesa. En 1795 es catedrático de clínica en la École de Médecine, en 1797 en la cátedra de medicina práctica del Collège de France. Une la teoría y la práctica, siguiendo y editando a los grandes maestros de clínica, Stoll, Boerhaave y Auenbrugger. Muy bueno en el pronóstico, es capaz de hacerlo sobre pintura, como tal vez no hizo su padre sobre el valor de los cuadros. Con Barthez, que viene de Montpellier, es nombrado médico de Napoleón, y en 1806 se publica su tratado sobre las enfermedades del corazón y los grandes vasos. Todas sus importantes contribuciones científicas son, desde luego, glosadas con detenimiento y precisión en la biografía que comento. Es nombrado Barón, Oficial de la legión de

6 Pabón, Jesús (1985), Franklin y Europa, Madrid, Sarpe, 55-104, Kant dijo de él que era un nuevo Prometeo que había robado el fuego al cielo, p. 57. 
Honor, Comandante de la orden de Reunión, miembro del Institut y de las Academias de Medicina y de Ciencias. Crea con otros el Journal de Médecine, Chirurgie et Pharmacie en 1817. Gran aficionado a la buena lectura, es devoto de Voltaire, Virgilio y Molière. Generoso, buen amigo, firme ante el poder, honesto en sus decisiones, deja así a un hermano sin empleo, pues no lo considera apto. En 1814 cae Napoleón y él sufre una apoplejía en 1815, muere en 1821. Sin hijos, es cuidado por su sobrino y ahijado, Scipion Corvisart, y quizás arrepentido por haber dejado a un hermano sin puesto, lo nombra heredero ${ }^{7}$. El fin de la descendencia, en esos Saturnos que devoran a sus hijos, es marca frecuente de esos hombres considerados superiores.

También en los comienzos de mi relación con la Sociedad Española de Historia de las Ciencias, en una intervención sobre las historias especializadas, hablé de la médica como una historia de linajes. Como es bien sabido, la medicina creada por los dioses, es regalada o bien robada por los semidioses y los héroes quienes la difunden, la difunden tanto que ha llegado hasta nosotros $^{8}$. Siempre con dificultades y pruebas, con delitos y castigos, estas carreras de obstáculos se inspiran en las biografías santas o heroicas, que sirven para modelar otras vidas ejemplares. Viniendo de una tradición artesanal - de la cocina, el ejército o la carpintería, se ha dicho de médicos y cirujanos-era necesario forjar sus biografías en forma de héroes, y ésta es tarea de los biógrafos y panegiristas 9 . Escribía Jean Genet que «la gloria de los héroes debe poco a la inmensidad de las conquistas, y todo al éxito de los homenajes; la Ilíada más que la guerra de Agamenón; las estelas caldeas que los ejércitos de Nínive» ${ }^{10}$. La tradición de los héroes, en especial Hércules y Prometeo, sigue siempre viva. Las vidas de emperadores o las de santos, que toman validez historiográfica con Carlyle y con Nietzsche siguen vigentes.

La biografía es también, entre otras cosas y como otras formas historiográficas, un esfuerzo por modelar el pasado al servicio del futuro, tanto para decirnos cómo se produjo el cambio en la ciencia, como para enseñarnos cómo

7 «Éloge de M. le Baron Corvisart», I, 92-129, sobre lecciones clínicas 107, diagnóstico sobre pintura 111. Frédèric Dubois es patólogo y biógrafo, escribe una patobiografía del emperador Augusto, August Hirsch herausgegeben (1962), Biographisches Lexicon, München und Berlin, Urban und Schwarzenberg, II, pp. 231-233 y 317.

8 PESET, J.L.(1987) «Historia del cuerpo, historia de la mente», en Antonio Lafuente, Juan José Saldaña (eds.) Historia de las ciencias, Madrid, CSIC, pp. 87-94.

9 Laín Entralgo, P. (1970), La medicina hipocrática, Madrid, Revista de Occidente; Pouchelle, M.C. (1983), Corps et chirurgie à l'apogée du Moyen-Age, París, Flammarion, 1983.

10 Tomado de ERIBON, D. (2004), Una moral de lo minoritario. Variaciones sobre un tema de Jean Genet, Barcelona, Anagrama, p. 22. 
debe ser el cambio en el presente. Así, pues, se mueve entre la historia de la ciencia entendida como racionalidad y la historia social entendida como determinación del medio social. Se oscila así entre la búsqueda de un modelo interno o un modelo externo. En general, se puede pensar que es la sociedad la que configura la forma de vida y de reconstrucción biográfica, pero también desde el campo de la lógica científica pueden llegar formas de modelar. Las biografías del arqueólogo tipo Indiana Jones o la del filósofo tipo Kant deben ser distintas. Pero incluso desde el individuo, desde su carácter o biología pueden llegar estímulos en este arte de modelar. En el caso de las doctrinas del «hombre de genio» está muy clara esta forma de concebir la forma de vida.

En fin, Manuel Vicent ha perfilado muy bien estas posibilidades, cuando ha escrito sobre el modelado del David y el Moisés por Miguel Ángel. Una música o un silencio pueden venir del interior del material a esculpir, según la obra de arte esté destinada a la belleza o a la gloria. Pero los encargos o el martillo del escultor no se pueden olvidar ${ }^{11}$. Nos habla de la fuerza del artista - y del científico - para extraer la vida que la tierra — madre también de la muerte- contiene en su seno, en su naturaleza. Es el mismo sentido que el poeta, así Pablo Neruda, emplea cuando se considera el labrador que saca el niño del vientre de la mujer, de la tierra. O el mismo que el campesino Miguel Hernández usará cuando quiera arrancar con su boca, con dentelladas secas y calientes, el hálito de su amigo muerto. La tierra, con sus propiedades de elemento sagrado y fisiológico, produce la vida y la muerte. Son sabidurías que el médico y el agricultor, el campesino y el poeta atesoraban.

¿Es distinto un científico? Sí y no, responde Antonello La Vergata. En las narraciones en que se resuelven sus biografías, los científicos muestran semejanzas y diferencias con otros personajes. Como en cualquier otra biografía, tiene el biografiado también una dinámica intersubjetiva y una lógica interna, debiendo la narración solucionar la tensión entre generalidad y especificidad. Toda narración de sucesos no inventados es recorrida por tensiones entre contexto y lógica interna, historia y estructura, época y sistema, que no se solucionan con introducciones anecdóticas o de panorama histórico ${ }^{12}$.

11 Texto de Manuel Vicent titulado «Mármoles», en El País de 6 de junio de 2004.

12 La Vergata, A. (1995), «Introduzione: storia e storie di scienziati», Intersezioni, XV, n. 1, pp. 3-20.Toma el profesor de Módena como base de su reflexión la técnica de la biografía victoriana, en especial sobre el círculo de Bloomsbury. Las películas de Ken Russell, también en este sentido estaban orientadas. La brevedad, la ironía, las cosas como se ven son las 
Se une con dificultad en la narración histórica contexto y psicología, individuo y sociedad, disgresiones y narración lineal, pues puede convertirse en una aproximación tipo sandwich. ¿Es posible respetar las ideas del autor, incluso sus ignorancias? Selección y valoración pueden encararse según nuestras ideas, o según las del autor; pero siempre la elección pertenece al historiador, quien hace nacer el hecho histórico. Se establece una jerarquía de los hechos, según el punto de vista del historiador, su campo de estudio, su tradición disciplinar, las cuestiones particulares que se propone, sus gustos, su capricho, o bien su humor y sentimientos. El biógrafo en su tarea esconde, o bien evidencia, por tanto deforma. Las omisiones son necesarias, dada la imposibilidad de completar, pues se llegaría a la exageración como en el mapa completo de Borges. Ignorar lo sucesivo, o convertir vida en destino son sus alternativas, haciendo al biografiado reflejo de su pasado, su presente o su futuro. La narratividad supone un estilo, pero también una intención tanto de escribir bien, como de pensar e intuir con acierto.

Así nos lo muestra el filósofo italiano en la novela de Flaubert Bouvard et Pécuchet. Dado que es imposible completar un importante retrato biográfico, es mejor elegir uno secundario; dado que sin imaginación la historia está llena de lagunas, una novela histórica es la mejor solución. Ante el fracaso científico de Flaubert, es su propio camino. La narración es la venganza contra la ciencia, la suprema forma de crítica. Toma de F. Savater algunas opiniones interesantes: la biografía es la novela de los que no saben escribirla, refugio para los que no creen en la historia o la deploran, pero se sienten fascinados por el pasado. En fin, son vistas las biografías como un atajo o un compendio, serían divulgación científica, pero también relación entre diversos públicos o especialistas. Acortan distancias entre el lector y el personaje. La biografía sería para La Vergata como un refugio, para evitar la indagación causal que los filósofos habían necesitado antes de la posmodernidad.

Es importante, como señalan Shortland y Yeo, tener en cuenta la psicología del biógrafo. Tomando como ejemplo la biografía de Newton e inmediatas declaraciones de Westfall, nos aportan interesantes comentarios. Si bien se pretexta un alejamiento del autor, sin duda las ideas religiosas de ambos motivaron el origen y curso de la obra. Se busca por el autor un yo ideal, que puede ser el del biografiado, el del biografiado en el biógrafo o el de mismo biógrafo. Hay una intrusión del biógrafo en busca de la verdad, en la elección del biografiado, pero también en la obra de arte en que queda la organización

indicaciones de estos biógrafos. Shortman y Yeo añaden la edulcoración de muchas de las biografías victorianas. 
de la obra. Cuándo y cómo aparece el autor, es esencial para su intelección. Hay dos tradiciones, la de búsqueda de una moral intangible y solitaria, y la de aumento de la tradición del grupo, es decir genio e intelectual, o enano en hombros de gigantes.

Se puede recuperar lo personal, pero también la sociología de una comunidad científica, como sucede tras la revolución científica ${ }^{13}$. Es antiguo, por tanto, el intento de la sociología por establecer el modelo del «científico», así sucede en los ejemplos clásicos de Max Weber, o bien de Thomas Merton. Más recientes $\mathrm{y}$, sin duda, de gran interés son los intentos que desde Francia nos vienen, así la caracterización del sabio ilustrado por Didier Masseau, o bien la introspección de Pierre Bourdieu sobre su propia labor como científico. Dentro de nuestra cultura podemos señalar algunas modelaciones de interés, así las primeras biografías de José Antonio Alzate, considerado como un santo ${ }^{14}$. O bien, la repercusión en las introducciones a las vidas de los grandes médicos de Pedro Laín de las fases en que los alemanes consideran las vidas de sus científicos, la de aprendizaje, la de viajero y la de maestría.

Pero para muchos autores, la biografía sería un terreno hoy en día necesario para el debate historiográfico. Para algunos es un método más, necesario pero complementario, pero para otros puede ser el mejor, o incluso el único. Señala el mismo La Vergata que nos hallamos ante problemas de historia interna y externa, de relación entre la lógica y los contenidos, de la teoría, el desarrollo psicológico individual, las corrientes intelectuales y las fuerzas sociales. En consecuencia, subraya las repercusiones del análisis de estas relaciones sobre el concepto de objetividad científica. Para algunos autores, por tanto, es necesario enfrentarse de forma decidida con estas novedades. En especial si se reconoce una especificidad propia al hombre de ciencia, incluso aunque ésta varíe en el contexto de las diferentes disciplinas, desde la matemática a la sociología en ambos extremos. Según La Vergata la actividad del científico, a diferencia del artista, no se reduce a su experiencia subjetiva. ¿Y la del filósofo, digo yo?

La biografía de sabio, ¿sirve para comprender la ciencia o el contexto, sirve tan solo para comprender al hombre? La ciencia no se trataría de un acon-

13 Shortland, M.; Yeo, R. (eds) (1996), «Introduction», en Telling lives in science. Essays on scientific biography, Cambridge University Press, pp. 1-44.

14 MasseaU, D. (1994), L'invention de l'intellectuel dans l'Europe du XVIIIe siècle, París, PUF; Bourdeu, P. (2003), El oficio de cientifico, Barcelona, Anagrama. PeSET, J.L. (1987), Ciencia y libertad, Madrid, CSIC, pp. 29-37. 
tecimiento azaroso, sino que una compleja trama psicológica y social la permite. No es fácil creer en el hallazgo casual ${ }^{15}$. Insiste La Vergata en la relación entre determinismo y contingencia, entre libertad y necesidad que el estudio de una biografía supone. Señala en Robert M. Young la biografía como historiografía total y radical (sustituye al marxismo), que recupera el sentido de individualidad e historicidad, la integración de lo público y lo privado, de lo interno y lo externo, es una disciplina nueva dentro de la ya compleja historiografía del cambio de siglo. La psicohistoria, el psicoanálisis, las fuerzas supraindividuales constituyen la mente individual. La esencia está en las articulaciones y en las mediaciones. También señala el italiano la entrada de su colega Pietro Redondi en el debate historiográfico, pues ante la crisis del método único actual, el de la biografía sería un precioso refugio. Los procesos de cambio o conservación científica llaman al centro de su método al sujeto cognoscente.

Incluso René Taton admite un notable papel a las biografías, pues «siendo cada descubrimiento o cada innovación científica, al menos en su detalle, la obra de individuos particulares, es a través de éstos que intervienen los diversos elementos que la condicionan, sean psicológicos, internos a la ciencia en cuestión o externos a ella. La biografía científica aparece de esta manera como la mejor vía para estudiar el proceso de creación y para analizar las influencias respectivas entre sus diferentes elementos» ${ }^{16}$. Así, entre la ambición totalizante y la fuga de los problemas teóricos, queda un arte, quedan buenos trabajos. Y buenas ventas, digo yo. Sería una forma de evitar esos libros secretos, de los que López Piñero tanto se lamenta.

En esta búsqueda de la diferencia del científico, pariente del artista o del filósofo, se le aplica el marchamo de «hombre de genio». También La Vergata nos dice que el insondable concepto de genio tiene tres funciones: redimir lo irreductible humano, liberar al lector del complejo de inferioridad, crear un mito de creatividad indiferenciada... en los tres supuestos la biografía es la solución al enigma. La atracción de la narración de lo particular humano haría abdicar de la reflexión filosófica. Ante la forma lógica de la ciencia dura, se alza la intuición y la narración de los sucesos históricos, particulares, únicos e irrepetibles, que por tanto no pueden ser explicados. La autobiografía, prosigue el filósofo italiano, es el terreno más minado, se interpreta la ciencia desde valores de algunos episodios, de una valoración unitaria y parcial, de su

15 Roberts, R.M. (2004), Serendipia, Madrid, Alianza Editorial.

16 TATON, R. (1897), «Las biografías científicas y su importancia», en Antonio Lafuente, Juan José Saldaña (Coords.), Historia de las ciencias, Madrid, CSIC, pp. 73-85. 
propio ideal de la ciencia. El genio nos presenta en su escrito su autodefensa, que considera su último recurso, su última posibilidad, ante un público externo o interno, quiere dar sentido y coherencia a la vida, pero siempre ante la muerte, se debe añadir. En las autobiografías de Rousseau o de Torres Villarroel está bien presente este carácter ${ }^{17}$.

Quizá, como señala La Vergata, la tradición del estudio del genio tiene tanto el intento de recuperar desde las voces armoniosas de la narración, lo humano, lo único e irrepetible, por tanto inefable, como el de fuga de la racionalidad científica o del determinismo social. Pero sin duda la biografía, y todavía más la autobiografía del genio tienen algo que decirnos. Desde luego esa justificación, ese modelar la propia vida, esa defensa y presentación última supone una intención, una necesidad quizá. El Ecce homo, de Montaigne, de Rousseau, de Nietszche algo nos presenta. Puede ser la superación de una prueba, la herencia de Hércules, de Adán, Prometeo y Fausto, con la transgresión que suponen sus atrevimientos. También el santo Grial y los caballeros, las vidas de santos, la de Cristo. Pero también la locura del aprendiz de sabio, como en Don Quijote de la Mancha. El saber como el sexo es sagrado, no puede ser transitado sin permiso, o la condena es la culpa y el dolor. La Biblia está llena de textos que cierran el saber o castigan el atrevimiento, en el árbol del bien y del mal, en el Paraíso está el origen del saber, o de la muerte, del placer o del trabajo. Pruebas, esfuerzos que son físicos y psíquicos, pero que también son sociales.

Insisten Shortland y Yeo en el interés en la marginalización del científico. Puede ser por el interés del propio sabio o bien de su historiador por insistir en los aspectos internalistas. Lo señalan en las autobiografías de Darwin, Einstein o Freud. Los historiadores — como sus severos personajes - buscan la objetividad, o bien la moral y la sabiduría. O se desprecia lo personal, o se recupera la lucha individual tras la autenticidad existencial. Se recupera un esencialismo psicológico, un carácter y una personalidad esenciales, intentando llegar al orden y la estructuración, que llevan al «mito de la coherencia personal». Pero también el intento puede ser presentar ejemplos de práctica de alguna comunidad científica, en especial en el campo de la retórica de la ciencia. Se trata de convencer a un tribunal, a los colegas o a la sociedad de que el discurso científico representa de forma cierta el orden de la naturaleza. Para ello se toma un modelo de hombre sin privacidad, sin pasiones e incluso sin naturaleza: se presenta una carrera,

17 Lange-Eichbaum, W (1942), Genie Irrsinn und Ruhm, $3^{\mathrm{a}}$ ed., München, Ernst Reinhardt, la primera edición es de 1927. PESET, J.L. (1999), Genio y desorden, Valladolid, Cuatro Ediciones. 
no una vida, que se presenta aburrida e incluso, lo que es más grave, innecesaria, ante la Verdad, el bien y la justicia ${ }^{18}$.

Junto a la pregunta acerca de la posible diferencia del científico, está esta otra: ¿El sabio nace, o se hace? Si el carácter es el destino, en afirmación clásica, esta pregunta es válida, no tan solo para el artista y el genio, sino también para el científico. Y la genialidad siempre está contaminada con la enfermedad, así en Lombroso, en Jaspers o en Kretschmer. Y en las enfermedades de los hombres de letras, asocia Tissot la patología al talento. La ciudad, la cultura, la prisa y la competencia hacen enfermar. La relación con la ciudad, con la modernidad está en estos autores, tan variados como Jean- Jacques Rousseau, Thomas Mann o Max Aub. Desde luego la psicología, el psicoanálisis, tienen mucho que decir. Personajes como Cardano, Cyrano, Queneau, Strindberg, etc. nos hablan acerca de la relación con el pecado, y el pecado del que quiere saber se relaciona con el misterio de la sexualidad.

Un reciente estudio de Javier Carreño nos trae de nuevo el recuerdo de las biografías escritas por Sigmund Freud. Aquéllas de artistas y/o científicos como Leonardo y Miguel Ángel, con más interpretación que información, y la del presidente Wilson, en la que sucede lo contrario. Si bien no se trata de un científico, trae a colación a un maestro de la oratoria. Las pulsiones amorosas familiares, en especial con el padre estructuran su vida. Su libido frustrada deriva al super-ego hacia la conformación de diversos órdenes, así la estructuración de equipos de deporte, de la Universidad de Princeton, de los Estados Unidos de América, o de la Sociedad de Naciones. La introducción de los preceptores en esa Universidad, o la formulación de los principios de la paz universal que contienen sus famosos puntos, devienen del enfrentamiento con un puritano padre de su personalidad femenina, de la que se avergüenza y deriva hacia fuertes dependencias, paterna, institucionales o amistosas. El príncipe de la paz es, una vez más, el Cristo que enferma, con brutales trastornos de la personalidad, y salva a la humanidad ${ }^{19}$.

$$
\text { * * * }
$$

18 SHORTLAND y YeO (1996).

19 Fue escrita en colaboración, véase CARREÑO, J. (2004), «El presidente estadounidense Thomas Wodrow Wilson», Cuadernos de psicoanálisis de Castilla y León, 8, 45-59. Un complejo diagnóstico marca esos colapsos frecuentes, que solucionaba en su hogar paterno o propio, o bien en Gran Bretaña, de donde procede su origen y mucha de su cultura literaria y oratoria. Admiró de forma firme a Gladstone. 
Tal como señala La Vergata, aunque la biografía del sabio tiene un cierto tono femenino, al menos en su público y, a veces, en su escritura, la mujer desaparece de su contenido. Pero no siempre es así. Veamos esas biografías, en que el carácter de la madre es esencial, como las de Maupertuis o Galois en el diccionario de Gillispie ${ }^{20}$. También la de una asesina estudiada por Carroy y Richard que es criminal e hipnotizadora, es sabia y científica, mujer con su sexualidad y fecundidad. La mujer puede desaparecer, como en las biografías de héroes y santos, de estudiantes o de sabios. Pero en otras ocasiones aparecen, como las esposas o las hijas que apoyan al padre o las madres que marcan a los hijos. En la vida de Alonso Quijano, tanto el amor como la protección hogareña son conformadores de sus angustias y refugios. La sexualidad tiene un papel transgresor, pues en el placer y en el pecado está también el descubrimiento de la verdad y de la vida; un papel de ubérrima supervivencia acompañada de la transgresión de lo sagrado. En la Ilustración la mujer es nivelada, pero en el Romanticismo se reacciona en forma de mujeres malvadas o heroínas insensatas. Los románticos y sus novelas se alejan de la armonía y la felicidad ${ }^{21}$.

Las terribles pruebas y marcas son expresión de esas mediaciones y articulaciones. Las trampas y transgresiones muestran la relación con dios, la patria y la cultura, la relación del yo con la fama y la gloria ${ }^{22}$. El científico nutre su Yo al defender su primer descubrimiento, su sabiduría que supera al espacio y al tiempo. Nos lo muestran así en las primeras firmas en las piedras de las catedrales, en las de artistas renacentistas.... que conocen la astrología y la alquimia, por tanto al demonio. Es distinto al sentido tradicional de autoría, dentro del cual el rey Alfonso X es considerado autor de las obras de sus monjes, sus judíos, sus astrónomos o sus letrados ${ }^{23}$. Del pecado surge la confesión, reconocimiento del dominio del sujeto sobre la naturaleza, del yo sobre el mundo. Hay un gran esfuerzo contra la naturaleza, para cambiar o permanecer, como señala La

20 Glass, B. (1974), «Maupertuis, Pierre Louis Moreau de», en Charles Coulston Gillispie (ed.), Dictionary of Scientific Biography, IX, pp. 186-189.

21 Bolufer, M. (1998), Mujeres e Ilustración, Valencia, Institución Alfonso el Magnánimo; Praz, M. (1968), La carne, la muerte y el diablo, Caracas, Monte Ávila. QUENEAU, R.(2004), En los confines de las tinieblas. Los locos literarios, Madrid, AEN. CARROY, J.; RICHARD, N. (2003), «Mathilde Frigard, científica y criminal. Cuando la historia de las ciencias se cruza con la crónica de sucesos», en Luis Montiel, Ángel González de Pablo (Coords.), En ningún lugar, en parte alguna. Estudios sobre la historia del magnetismo animal y del hipnotismo, Madrid, Frenia, pp. 171-192.

22 CiCERÓN (2004), El sueño de Escipión, Barcelona, El Acantilado.

23 JiMËNEZ, A. (1971), Historia de la Universidad española, Madrid, Alianza, p. 85. 
Vergata ${ }^{24}$, pues la evolución humana es tanto biológica, como social y cultural, tal como señalan Rousseau y Wartofski ${ }^{25}$. Pero quizá, como señalan Shortland y Yeo en el estudio de F. Manuel, la obra de Newton ¿dependa del carácter de su madre? ${ }^{26}$

24 LA Vergata, A. (2002), «Darwinismo sociale e lamarkismo sociale: 'lotta' e 'sforzo'», en M. A. Puig Samper, Rosaura Ruiz, Andrés Galera (eds.), Evolucionismo y cultura, Junta de Extremadura, UNAM, Doce Calles, Madrid, pp. 183-198.

25 WARTOFSKY, M. W. (1975), «Organs, organisms and disease: human ontology and medical practice», en T. Engelhardt y S. F. Spicker (eds.), Evaluation and Explanation in the Biomedical Sciences, Dordrecht, Boston, D. Reidel Publishing Company, pp. 67-83.

26 No sé si se han empezado los estudios sobre las mujeres de los científicos, en el terreno de las esposas de los literatos ya se ha avanzado, véase Golin, C. (2002), «Entrevistas con mulheres de escritores brasileiros histórias silenciosas da creaçao», Aletria revista de estudos de literatura, 9, 106-116. Se considera un camino hacia la historia privada de la literatura y la historia cultural de género. Se analiza el literato burgués, y la mujer como creadora de un cosmos que identifica con la casa. 